\title{
Aa. Vv., «Le Courrier balzacien»
}

\section{Annalisa Bottacin}

\section{(2) OpenEdition}

\section{Journals}

\section{Edizione digitale}

URL: https://journals.openedition.org/studifrancesi/39558

DOI: 10.4000/studifrancesi.39558

ISSN: 2421-5856

\section{Editore}

Rosenberg \& Sellier

\section{Edizione cartacea}

Data di pubblicazione: 1 décembre 2004

Paginazione: 387

ISSN: 0039-2944

\section{Notizia bibliografica digitale}

Annalisa Bottacin, «Aa. VV., «Le Courrier balzacien»», Studi Francesi [Online], 143 (XLVIII | II) | 2004,

online dal 30 novembre 2015, consultato il 19 mai 2021. URL: http://journals.openedition.org/ studifrancesi/39558 ; DOI: https://doi.org/10.4000/studifrancesi.39558

Questo documento è stato generato automaticamente il 19 mai 2021.

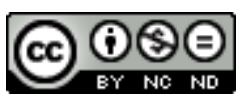

Studi Francesi è distribuita con Licenza Creative Commons Attribuzione - Non commerciale - Non opere derivate 4.0 Internazionale. 


\section{Aa. Vv., «Le Courrier balzacien»}

\section{Annalisa Bottacin}

\section{NOTIZIA}

«Le Courrier balzacien», Nelle Série, N 88, 3e trimestre 2002, pp. 67.

1 Il fascicolo si apre con l'intervento di Anne-Marie BARON (Balzac, ou les hiéroglyphes de l'imaginaire, pp. 3-17), in cui l'A. traccia le linee fondamentali del rapporto tra Balzac e la scrittura, oggetto del suo recente studio pubblicato da Champion nel 2002. Secondo Baron, la scrittura rappresenta, per Balzac, la «face cachée de la comédie humaine», «elle est aussi et surtout cryptique» (p. 7) ed essa costituisce lo strumento privilegiato dallo scrittore per connotare, all'interno dell'universo narrativo, le potenzialità semantiche, poetiche e spirituali della parola. Se La Comédie humaine, sottolinea in maniera forse troppo perentoria l'A., "doit se lire comme une oeuvre mystique», l'écriture hiéroglyphique", «à la fois figurative, phonétique et sacrée», si vede investita di una «haute mission, celle de faire accéder le lecteur à une véritable révélation» (p. 16). Da questo punto di vista, conclude l'A., il rapporto tra Balzac e la scrittura si configura come «une conduite magique liée à un volontarisme imaginaire et à la croyance - légitime chez un romancier - à un pouvoir surnaturel du langage» (p. 17).

2 Jean-Pierre GALVAN e Jacques PAPIN (Trois lettres de lecteurs de Balzac, pp. 18-23) curano la pubblicazione di tre lettere indirizzate da altrettanti lettori al direttore de «Le Siècle» (Louis Desnoyer), i quali esprimono le loro reazioni di disappunto alla lettura di Béatrix, romanzo pubblicato in forma di 'feuilleton' da «Le Siècle» tra il 13 e il 26 aprile 1839.

3 Nel breve saggio di Laure Doumens (Une feuille d'“Eugénie Grandet", pp. 24-27) sono riprodotte le due pagine di Eugénie Grandet (nell'edizione pubblicata da Charpentier nel 1839), oggetto di revisione da parte di Balzac, le quali «semblent être seules, pour ce roman, à pouvoir nous renseigner sur cette étape déterminante du travail de l'auteur caractéristique de son souci de perfection: la correction en vue d'une nouvelle édition» (p. 25). 
4 Questo numero della rivista si chiude con la pubblicazione, a cura di Thierry BoDIN, del denso studio su Balzac scritto, nel 1841, da Louis de Loménie (sotto lo pseudonimo di «Un homme de rien»): il saggio in questione fa parte di una serie di studi biografici che formano la Galérie des contemporains illustres, edita dalla libreria Ducrocq tra il 1840 e il 1847 (Balzac vu par Louis de Loménie, pp. 28-67). 